\title{
Bir Türk popülasyonunda üçüncü molar dişlerin gelişiminin radyografik olarak değerlendirilmesi: yaş, cinsiyet ve çene karşılaştırması
}

Fatma Deniz Uzuner, Emine Kaygısız, ${ }^{*}$ Nilüfer Darendeliler, Altuğ Yeniay

Ortodonti Anabilim Dalı, Gazi Üniversitesi Diş Hekimliği Fakültesi, Ankara, Türkiye

\section{ÖZet}

AmAÇ: Bu çalışmanın amacı Türk toplumunda 12-17 yaş aralığındaki bireylerde üçüncü molar dişlerin gelişim dönemlerini çeneler, yaş ve cinsiyet açısından karşılaştırarak tespit etmektir.

GeREÇ Ve YönTEM: 12-17 yaşları arasındaki 322 (162 kız, 159 erkek) Türk bireye ait panoramik film değerlendirildi. ÇaIsşma grubuna sol tarafta üst ve alt üçüncü molar dişleri mevcut olan bireyler dahil edildi. Birey sayısı yaş gruplarına ve cinsiyetlere göre denkleştirildi. Tüm değerlendirmeler, karanlık bir odada tek bir deneyimli ortodontist tarafından, hastaların yaş ve cinsiyet bilgisi bilinmeden yapıldı.Üst ve alt üçüncü molar dişlerin gelişim evreleri Demirjian metoduna göre A-H arasında sınıflandırıldı. Her bir gelişim evresine 1 den 8'e kadar sayısal değer verildi. Üçüncü molar diş gelişiminin cinsiyet, yaş ve çeneler bakımından karşılaştırılmasında Mann-Whitney U testi kullanıldı. İstatistiksel anlamlılık düzeyi $p<0.05$ kabul edildi.

BULGULAR: Araştırmacı içi tekrarlanabilirlilik katsayısı 0.85 olarak bulundu. Tüm yaşlarda, üçüncü molar diş gelişim evresi bakımından cinsiyetler ve çeneler arasında istatistiksel olarak anlamlı farklılık bulunmadı. Üçüncü molar diş kron oluşumunun her iki cinsiyette ve çenede 14 yaşında tamamlandığı gözlendi. Kökün yarısı ile 2/3'ünün gelişiminin her iki cinsiyette ve çenede en erken 15 yaşlarında olduğu saptandı. Kök gelişiminin tamamlanması kızlarda en erken 16, erkeklerde 17 yaşlarındadır.

Sonuç: Her bir yaş grubunda gerek cinsiyet gerekse çeneler arasında üçüncü molar dişlerin gelişimi bakımından fark saptanmadı.

Anahtar Kelimeler: Azıdişi, üçüncü; diş erüpsiyonu; diş kalsifikasyonu

Kaynak Göstermek İçin: Uzuner D, Kaygısız E, Darendeliler $N$, Yeniay A. Bir Türk popülasyonunda üçüncü molar dişlerin gelişiminin radyografik olarak değerlendirilmesi: yaş, cinsiyet ve çene karşılaştırması Acta Odontol Turc 2015;32(3):130-5.

Makale gönderiliş tarihi: 15 Ocak 2015; Yayına kabul tarihi: 14 Mart 2015 *iletişim: Emine Kaygısız, Gazi Üniversitesi Diş Hekimliği Fakültesi, Ortodonti Anabilim Dalı, 06510 Emek, Ankara, Türkiye;

e-posta: dt.emineulug@mynet.com
YAYIN HAKKI: () 2015 Uzuner ve ark. Bu eserin yayın hakkı Creative Commons Attribution License ile ruhsatlandırılmıştır. Sınırsız kullanım, dağıtım ve her türlü ortamda çoğaltım, yazarlar ve kaynağın belirtilmesi kaydıyla serbesttir.

[Abstract in English is at the end of the manuscript]

\section{Giriş}

Üçüncü molar dişler, gerek morfolojik gelişim süreçleri gerekse de dental ark üzerinde yerleşmeleri açısından en fazla varyasyon gösteren dişlerdendir. ${ }^{1,2}$ Eksikliklerinin Türk toplumunda \%22.7 oranında olduğu bildirilirken, ${ }^{3}$ bu oranın diğer toplumlarda ise $\% 7$ ile 32.4 arasında değiştiği belirtilmektedir. ${ }^{4-6}$

Mevcut olan üçüncü molar dişler ise dental ark üzerinde yerini alamayıp sıklıkla gömülü kalabilmektedir. Özellikle alt üçüncü molar dişlerin gömülülüğünde, bu dişlerin geç dönemdeki gelişimleri ve alt çenenin filogenetik evrimi nedeniyle yeterli yerin sağlanılamaması etkendir.1,2,7 Gömülü kalan üçüncü molar dişler, perikoronitis gelişimi, ikinci moların distalinde ve/veya üçüncü moların kendisinde çürük gelişimi, odontojenik tümör oluşumu, miyofasiyal ağrı, ayrıca primer veya sekonder çapraşıklık oluşumu ile ilişkilendirilmektedir. ${ }^{1} \mathrm{Be}$ lirtilen bu olası olumsuzlukların önlenmesinde, üçüncü molar dişlere çekim endikasyonu kararı verilir. Lysell ve Rohlin ${ }^{1}$ üçüncü molar diş çekilme nedenlerini, \%27 profilaktik, \%25 perikoronitis, \%14 ortodontik, $\% 25$ pulpitis ve çürük, \%3 kist, tümör, kök rezorpsiyonu ve \%18 diğer faktörler olarak bildirmektedir.

Profilaktik amaçlı çekimler, özellikle kist veya enfeksiyon gelişimini önlemeye yöneliktir. ${ }^{8,9}$ Ortodontik amaçı çekimler ise birinci ve ikinci molar dişlerin distalizasyonu için posteriorda yeterli yerin sağlanmasına ve ortodontik tedavi sonrasında gelişebilecek geç dönem alt keser çapraşıklığın önlenmesine yöneliktir. ${ }^{8,9} \mathrm{Geç} \mathrm{dönem} \mathrm{alt}$ keser çapraşıklığında üçüncü molar dişlerin etkisinin olup olmadığı halen tartışmalı bir durumdur. Üçüncü molar dişlerin sürmesi sırasında oluşan kuvvetin meziyal komponentinin dental ark boyunca yayılması, dişlerin meziyal migrasyonu ve keser bölgesinde bunun en fazla olması nedeniyle ön bölgede çapraşıklık meydana 
geldiği savunulmaktadır. ${ }^{10}$ Üçüncü molar diş ile alt keser çapraşıklığı arasında bir ilişki tanımlayan çalışmalar ${ }^{11,12}$ dışında hiç bir ilişki bulamayan çalışmalar da mevcuttur. ${ }^{13,14}$ Niedzielska ${ }^{11}$ üçüncü molar diş sürerken uygun yer mevcut ise normal konumdaki dişlere herhangi bir etkisi olmadığını, tersi söz konusu olduğunda üçüncü molarların çapraşıklığa neden olacağını belirtmektedir.

Profilaktik ve/veya ortodontik amaçlı çekim endikasyonu konulduktan sonra hastaya en az rahatsızlık oluşturacak doğru zamanın belirlenmesi önemli bir konudur. Genel görüş, ileri yaştansa erken dönemde çekilmeleri yönündedir. ${ }^{15,16}$

Toplumlar arasında üçüncü molar diş gelişimleri açısından farklılıklar bildirilmektedir.,5,17-26 Dolayısıyla önerilen çekim zamanları arasında da farklılıklar gözlenebilmektedir. Yapılan literatür değerlendirmesinde, Türk toplumunda üçüncü molar diş gelişim evrelerini çeneler, cinsiyetler açısından değerlendiren az sayıda çalışmaya rastlanmaktadır. ${ }^{21,25,27} \mathrm{Bu}$ çalışmalar öncelikle adli tıpa yönelik olarak dişlerin gelişim evrelerinden kronolojik yaş ve/veya pubertal gelişimin belirlenmesine odaklanmış, geniş yaş aralığında, heterojen dağılım gösteren birey sayıları içermektedir. 3,21,25,27-29 Üst ve alt çenelerin her ikisinde de yirmi yaş dişin mevcut olduğu, cinsiyet ve yaş gruplarının hemen hemen eşit sayıda birey içerdiği bir çalışma grubuna rastlanılmamıştır. Bu nedenle bu çaIışmanın amacı, Türk toplumunda kronolojik yaşları 1217 yıl arasında olan bireylerde üçüncü molar dişlerin gelişim dönemlerini radyolojik görüntülerinde çeneler, yaş ve cinsiyet açısından karşılaştırarak tespit etmektir.

\section{Gereç Ve Yöntem}

Gazi Üniversitesi Diş Hekimliği Fakültesi Ortodonti Anabilim Dalında tedaviye alınmış olan yaşları 12-17 yıl arasında olan 322 (162 kız, 159 erkek) Türk bireye ait panoramik film değerlendirildi.

Çalışma grubuna, sol tarafta üst ve alt üçüncü molar dişleri mevcut olan bireyler dahil edildi. Üçüncü molar diş gelişimini etkileyecek herhangi bir sistemik rahatsızIığı veya beslenme bozukluğu olan, cerrahi işlem uygulanmış olan, daimi diş eksikliği olan bireyler ise çalışmaya alınmadı.

Birey sayısı, yaş gruplarına ve cinsiyetlere göre denkleştirildi. Üst ve alt üçüncü molar dişlerin gelişim evreleri Demirjian ve arkadaşlarının ${ }^{30}$ belirttiği şekilde A'dan H'ye göre sınıflandırıldı (Şekil 1). Her bir gelişim evresine 1 den 8'e kadar sayısal değer verildi.

Tüm değerlendirmeler, karanlık bir odada tek bir deneyimli ortodontist tarafından hastaların yaş ve cinsiyet bilgisi olmadan yapıldı.

Her bir grup için en düşük örnek sayısı $\alpha=0.05$ iken, 0.80 güç seviyesinde, 10 birey olarak tespit edilmiş ol- masına rağmen, bu çalışmada her bir yaş ve cinsiyet grubunda hasta sayısı 24 ve üstü olacak şekilde arttırıldı.

Dişlerin gelişim evrelerinin belirlenmesinde ölçüm tekrarlanabilirliliğinin değerlendirilmesi amacıyla ilk değerlendirmeden iki hafta sonra rastgele seçilen 50 bireye ait panoramik film üzerinde üçüncü molar dişlerin gelişim evreleri tekrar saptandı. İstatistiksel olarak, iki değerlendirme Kappa uyum testi ile karşılaştırıldı.

Üçüncü molar dişlerin gelişiminin cinsiyet, yaş ve çeneler bakımından karşılaştırılmasında Mann-Whitney $U$ testi kullanıldı. Tüm istatistiksel analizler SPSS 20.0 programında (IBM, Armonk, NY, ABD) yapıldı. İstatistiksel anlamlılık düzeyi $p<0.05$ olarak kabul edildi.

\section{BULGULAR}

Tüm değerlendirmelerin tekrarlanabilirliliği yüksek bulundu (Cohen'in kappa katsayısı=0.85).

Yaş gruplarına göre kız ve erkek bireylerin dağılımı ile üçüncü molar dişlerin gelişim evrelerinin skor değerleri ve istatistiksel karşılaştırmaları Tablo 1'de gösterildi.

Tüm yaşlarda, üçüncü molar diş gelişim evresi bakımından cinsiyetler arasında istatistiksel olarak anlamlı bir farklılık bulunmadı ( $p>0.05)$.

Tüm yaşlarda, her iki cinsiyette üst ve alt üçüncü molar diş gelişim evreleri bakımından da istatistiksel olarak anlamlı farklılık bulunmadı ( $p>0.05)$.

Üçüncü molar diş kron oluşumunun (D evresi=4) her iki cinsiyette ve çenede 14 yaşında tamamlandığı gözlendi. Kökün yarısı ile 2/3'ünün gelişiminin ( $E=5$ ve $F$ evresi=6) her iki cinsiyette ve çenede en erken 15 yaşlarında olduğu saptandı. Kök gelişiminin tamamlanmasının ( $\mathrm{H}$ evresi=8) kızlarda en erken 16 , erkeklerde 17 yaşlarında olduğu bulundu.

Her iki cinsiyette ve yaş gruplarında, genel olarak üst üçüncü molar dişlerin gelişiminin alt üçüncü molar dişlerden daha ileri olduğu görülmekle birlikte istatistiksel olarak anlamlı bir farklılık saptanmadı ( $p>0.05)$.
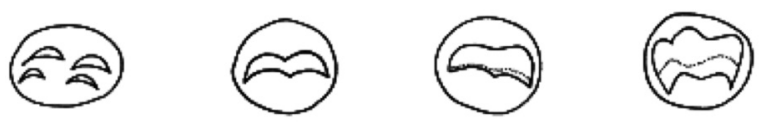

A

B

C

D
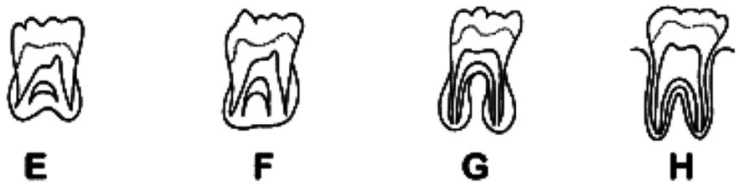

Şekil 1. Üçüncü molarların Demirjian ve ark. (1973) tarafından A'dan H'ye belirlenen gelişim evrelerinin şematik gösterimi (Skorlama $A=1, B=2, C=3, D=4, E=5$, $F=6, G=7, H=8$ ) 


\section{TARTIŞMA}

Dişlenmenin gelişimi cinsiyetler, çeneler ve toplumlar arasında farklılık gösterebilmektedir. ${ }^{4,5,31} \mathrm{Bu}$ araştırmada 12-17 yaşlar arasındaki Türk bireylerde üçüncü molar dişlerin yaşa, cinsiyete ve üst/alt çenelere göre gelişimi karşılaştırmalı olarak değerlendirildi.

Başkent olarak Ankara'nın çevre illerden ve bölgelerden göç almasına bağlı olarak heterojen bir etnik yapı göstermesi, beraberinde farklı illerden sağlık hizmeti almak için hastaların başkente gelmesinden dolayı bu çalışmadaki örneklemin Türk populasyonunu yansıttığı düşünülmektedir.

Bu çalışmada, diğer çalışmalardan ${ }^{21,25,27}$ farkı olarak her bir yaş, cinsiyet ve çenelere göre birey sayısı denkleştirildi. Ayrıca alt ve üst çenede üçüncü molar diş gelişimlerinin karşılaştırılması amacıyla, sağ ve sol taraf arasında olası gelişim farklıı̆ının ekarte edilmesine yönelik olarak sadece sol tarafta alt ve üst üçüncü molarların mevcut olduğu bireyler araştırma kapsamına alındı.

Üçüncü molar dişlerin gelişim evreleri, kesin değerlendirmelerin yapılabildiği basit bir yöntem olan Demirjian metodu ile tespit edildi. ${ }^{30} \mathrm{Bu}$ metotta, dişlerin gelişimi boyutsal ölçümlerden ziyade, şekilsel değişime ve kron-kök oranına bakılarak değerlendirilmektedir. Bu nedenle film magnifikasyonları, değerlendirmenin güvenilirliğini etkilememektedir. ${ }^{30}$

Bu çalışmada diğer çalışmalarla benzer şekilde tüm yaş gruplarında ve her iki cinsiyette diş gelişim evreleri bakımından bireysel farklılıklar gözlendi. ${ }^{29,31}$ Üçüncü molar dişlerin 12 yaşında her iki çenede ve cinsiyette kripta evresinde olduğu (A evresi) gözlenebilirken, 13 yaşından itibaren $B$ evresine geçilmiş olduğu tespit edildi. Bu çalışmanın bulgularıyla benzerlik gösterecek şekilde Jung ve $\mathrm{Cho}^{32}$ üst çenede 12 , alt çenede 13 yaşından sonra kripta oluşumunun tamamlandığını bu yaşlardan sonra B evresine geçildiğini bildirmektedir. Liversidge ${ }^{22}$ çalışmasında üçüncü molar dişin kripta oluşumunun 6-14 yaşlar arasında olduğunu belirtirken, farklı olarak diğer bir çalışmada Arany ve ark. ${ }^{4}$ ise, üçüncü molar dişin $A$ ve $B$ evrelerinin 14-18 yaşına kadar gözlendiğini bildirmektedir. Bu çalışmanın bulguları değerlendirildiğinde, Türk bireylerde üçüncü molar diş eksikliği tanısının konulmasında 12 yaşa kadar beklenmesi uygun olacaktır.

Çekim endikasyonu konulan üçüncü molar dişlerin en erken germ döneminde çekimi önerilmektedir. Germektomi yapıldığında cerrahi işlemin daha kolay olması, klinik komplikasyonlarının daha az oluşması, ve postoperatif iyileşmenin ileri yaştan daha hızlı olması gibi avantajları vardır. ${ }^{9}$ Ayrıca erişkinlerde en sık gözlenen komplikasyon olan lingual sinir hasarının germektomi yapıldığında daha az olduğu belirtilmiştir. ${ }^{33} \mathrm{Bu}$ dişlerin en erken 7-9 yaşlarında germlerinin oluştuğ ${ }^{16}$ görülse de germektominin 12-13 yaşlarından sonra yapılması önerilmektedir. Chiapasco ve ark. ${ }^{33}$ da germektomi için 14 yaşın daha uygun olduğunu bildirmektedir. Germektomi için en doğru zamana karar vermede dişin kron oluşu-

Tablo 1. Yaş, cinsiyet ve çenelere göre üçüncü molarların gelişimi

\begin{tabular}{|c|c|c|c|c|c|c|c|c|c|}
\hline \multirow[b]{2}{*}{ Yaş } & & \multirow[b]{2}{*}{$\mathrm{n}$} & \multirow[b]{2}{*}{ Ortalama } & \multicolumn{2}{|c|}{ Üst çene } & \multicolumn{4}{|c|}{ Alt çene } \\
\hline & & & & SS & Ortanca (Min-Maks) & Ortalama & SS & Ortanca (Min-Maks) & $p$ \\
\hline \multirow[t]{3}{*}{$12.00-12.99$} & $\mathrm{KIZ}$ & 30 & 3.7 & 0.88 & $4.0(1.0-5.0)$ & 3.4 & 0.83 & $3.0(1.0-5.0)$ & 0.170 \\
\hline & Erkek & 27 & 3.6 & 0.92 & $4.0(1.0-5.0)$ & 3.3 & 1.07 & $4.0(1.0-4.0)$ & 0.079 \\
\hline & $p$ & & & 0.900 & & 0.932 & & & \\
\hline \multirow[t]{3}{*}{$13.00-13.99$} & $\mathrm{KIZ}$ & 24 & 3.9 & 0.52 & $4.0(2.0-5.0)$ & 3.4 & 0.80 & $4.0(3.0-5.0)$ & 0.497 \\
\hline & Erkek & 26 & 3.4 & 0.62 & $4.0(3.0-5.0)$ & 3.8 & 0.68 & $4.0(3.0-6.0)$ & 0.426 \\
\hline & $p$ & & & 0.464 & & 0.595 & & & \\
\hline \multirow[t]{3}{*}{$14.00-14.99$} & $\mathrm{KIz}$ & 27 & 4.5 & 0.69 & $4.0(3.0-7.0)$ & 4.2 & 0.76 & $4.0(3.0-7.0)$ & 0.105 \\
\hline & Erkek & 26 & 4.7 & 0.85 & $5.0(4.0-6.0)$ & 4.4 & 0.86 & $4.0(3.0-6.0)$ & 0.283 \\
\hline & $p$ & & & 0.354 & & 0.140 & & & \\
\hline \multirow[t]{3}{*}{$15.00-15.99$} & $\mathrm{~K} \mathrm{Iz}$ & 27 & 5.0 & 0.78 & $5.0(3.0-7.0)$ & 4.8 & 0.98 & $5.0(3.0-7.0)$ & 0.551 \\
\hline & Erkek & 27 & 5.3 & 0.85 & $5.0(4.0-7.0)$ & 4.9 & 1.20 & $5.0(3.0-6.0)$ & 0.267 \\
\hline & $p$ & & & 0.247 & & 0.680 & & & \\
\hline \multirow[t]{3}{*}{$16.00-16.99$} & $\mathrm{~K} \mathrm{Iz}$ & 30 & 5.7 & 1.02 & $6.0(4.0-8.0)$ & 5.4 & 0.90 & $5.0(4.0-8.0)$ & 0.394 \\
\hline & Erkek & 26 & 5.7 & 1.12 & $6.0(4.0-7.0)$ & 5.5 & 1.01 & $6.0(4.0-7.0)$ & 0.579 \\
\hline & $p$ & & & 0.946 & & 0.517 & & & \\
\hline \multirow[t]{3}{*}{$17.00-17.99$} & $\mathrm{KIz}$ & 25 & 6.3 & 1.24 & $6.0(4.0-8.0)$ & 6.3 & 1.09 & $6.0(4.0-8.0)$ & 0.913 \\
\hline & Erkek & 27 & 6.6 & 1.40 & $7.0(4.0-8.0)$ & 6.5 & 1.21 & $7.0(4.0-8.0)$ & 0.522 \\
\hline & $p$ & & & 0.365 & & 0.479 & & & \\
\hline
\end{tabular}

SS: Standart sapma, $\mathrm{n}$ : birey sayısı 
munun tamamlandığı D evresinin zamanının belirlenmesi önem kazanmaktadır. Bu çalışmada, her iki cinsiyet ve çenede üçüncü molar dişlerin kron oluşumunun 14 yaş civarında tamamlandığı (D evresi) bulundu. Kron oluşumunun tamamlanma yaşı, diğer çalışmaların sonuçları ile kıyaslandığında Koreli bireylere benzer, Japon ve Alman bireylerden erken, İranlı bireylerden geçtir. 4,7,24,32 Bu çalışmanın bulgularıyla benzer olarak Orhan ve ark. ${ }^{21}$ Türk toplumunun ortalama 14.9 yaşında $D$ evresine eriştiğini belirtmektedirler. Karataş ve ark. ${ }^{28}$ erkeklerin 13.1 , kızların 12.8 yaşında D evresinde olduğunu, her iki cinsiyette de 15 yaş sonrası E evresine geçildiğini bildirmektedirler. Cantekin ve ark. ${ }^{34}$ ise ortalama $13^{\prime}$ lü yaşlarda $D$ evresine erişildiğini belirtmektedirler. Çalışmanın bulguları göz önünde bulundurulduğunda,Türk toplumu için kron oluşumunun tamamlandığı 14 yaş, germektomi için en uygun zaman olarak önerilebilir.

Postoperatif ağrı, enfeksiyon ve şişlik şikayetinin üçüncü molar diş köklerinin 2/3'ünün oluştuğu dönemde daha az olduğu, kök gelişiminin tamamlanmasından önce çekimin daha faydalı olduğu vurgulanmaktadır. ${ }^{16}$ Üçüncü molar dişlerin profilaktik çekimi için en uygun evrelerden biri olarak belirtilen diş kökünün 1/2'si ile 2/3'ünün oluştuğu dönemler ( $E$ ve $F$ evreleri) bu çalışmanın bulgularına göre Türklerde 15-16 yaşları arasındadır. Jung ve $\mathrm{Cho}^{32}$ her iki çenede en erken 14 yaşında kökün 2/3 oluşumunun tamamlandığını bildirmektedir. Gay-Escoda ve ark. ${ }^{7}$ İspanyollar için bu dönemin 16-18 yaşlar arasında olduğunu bildirmektedirler. Araştırmalarda elde edilen farklı bulgular toplumlar arasında diş gelişimleri bakımından gözlenen farklılıklara, örneklem sayısı ve metodolojik farklılıklara bağlı olabilir.

Kök gelişiminin ise en erken her iki çenede kızlarda 16 yaşında, erkeklerde 17 yaşında tamamlandığı saptandı (H evresi).Diğer toplumlarla karşılaştıııldığında kök gelişiminin tamamlanması Japonlardan erken Korelilerle benzer zamanlardadır. ${ }^{4,32}$

Demirjian metoduyla üçüncü molar dişlerin gelişim evrelerinin değerlendirildiği çalışmaların bazılarında erkeklerin kızlara göre daha erken gelişim gösterdiği bildirilirken, 4,28,32 bazılarında da cinsiyetler arasında fark olmadığı bildirilmektedir. ${ }^{19} \mathrm{Bu}$ çalışmada da, cinsiyetler arasında üçüncü molar diş gelişimi bakımından fark bulunmadı. Benzer şekilde Karataş ve arkadaşlarının ${ }^{28}$ Güney Anadolu bölgesindeki 6-16 yaş arasındaki Türk çocuklarında yaptıkları çalışmada üçüncü molar dişlerin gelişimlerinde istatistiksel olarak cinsiyetler arasında fark bulunmamıştır.

Çocukluk döneminde kız çocuklarında diş gelişiminin erkeklere nazaran daha ileride olduğu ${ }^{35}$ ancak geç pubertal dönemde anabolik sterodilerin artan etkisi ile oluşan hormonal değişimlerin de katılımı ile erkeklerin ileriye geçebildiği bildirilmektedir. Özellikle üçüncü molar diş gelişimlerinin son evrelerinde erkeklerin daha ileri gelişim gösterdiği vurgulanmaktadır. ${ }^{36}$ $\mathrm{Bu}$ bulguyu destekler şekilde Jung ve $\mathrm{Cho}^{32}$ üçüncü molar dişlerin $\mathrm{D}-\mathrm{H}$ gelişim evrelerine erkeklerin istatistiksel olarak anlamlı seviyede kızlardan daha erken ulaştığını bildirmektedirler. Bu çalışmada da istatistiksel olarak anlamlı bulunmamakla beraber 12-13 yaşlarında her iki çenede gelişimin erkeklerde daha geride iken, 14-17 yaşlarında ise erkeklerde daha ileride olduğu gözlendi.

Bu çalışmada, üçüncü molar diş gelişimlerinin üst çenede alt çeneye göre daha ileride olduğu görülse de istatistiksel olarak çeneler arasında bir fark bulunmadı. Bu bulguyu destekler şekilde Türk toplumunda Karataş ve ark. ${ }^{28}$ ve Karadayı ve ark. ${ }^{37}$ her iki cinsiyette sağ-sol üst ve alt üçüncü molar dişlerin gelişimi bakımından fark bulmadıklarını bildirirken, Orhan ve ark. ${ }^{21}$ üst arkta gelişimin daha ileride olduğunu bildirmektedir.

Farklı toplumlarda yapılan çalışmalarda, farklı sonuçlar bildirildiği görülmektedir. ${ }^{17,18}$ Olze ve ark. ${ }^{19}$ çeneler arasında fark olmadığını, farklı olarak Solari ve ark..$^{38}$ Hispaniklerde, Martin-de las Heras ve ark. ${ }^{20}$ İspanyol ve Mağribilerde, Arany ve ark. ${ }^{4}$ Japonlarda üçüncü molar diş gelişiminin üst arkta daha ileride olduğunu bildirmektedirler. Jung ve $\mathrm{Cho}^{32}$ Koreli bireylerde yaptığı değerlendirmede üçüncü molar dişlerin $A-D$ ve $H$ evrelerine üst çenede daha erken yaşta ulaşıldığını belirtmektedir. Bu çalışmanın bulgularıyla diğer çalışmaların bulguları arasında gözlenen farklılık, araştırmaların birey sayısına, metodolojisine, örneklem topluluğuna, yaşa bağlı olabilir.

Dişlerin gelişiminde genel olarak toplumlar arasında farklılıklar gözlenmekle birlikte aynı toplumda da bireysel varyasyonlar göze çarpmaktadır. Üçüncü molar dişlerin gerek ortodontik gerekse profilaktik amaçla çekimi kararlaştırıldığında klinisyenin birey için hangi yaş dilimleri arasında çekimin en az komplikasyonla gerçekleştirebileceğini bilmesi önem kazanmaktadır. Özellikle pedodonti ve ortodonti kliniklerinde daimi dişlenme sürecinin takibinde yalnızca dişlerin dental arkta yerleşimlerinin değerlendirilmesi dışında üçüncü molar gelişiminin de detaylı takibi yararlı olacaktır. Ortodontik tedavi sonrasında olası gözlenen geç dönem çapraşıklıkta yeterli yer olmayan üçüncü molarların etkili olabileceği dikkate alınarak bu dişlerin gelişimlerinin tamamlanması süreci tedavi protokolunun içine dahil edilmelidir. Bu çalışmanın bulguları pedodonti, ortodonti ve cerrahi kliniğinde klinisyene yön verici olabilecektir.

\section{Sonuç}

12-17 yaşlar arasında üçüncü molar diş gelişimleri bakımından kız-erkek ve üst ve çeneler arasında fark bu- 
lunmadı. Üçüncü molar diş kron oluşumunun her iki cinsiyette ve çenede 14 yaşında tamamlandığı, kökün yarısı ile 2/3'ünün gelişiminin her iki cinsiyette ve çenede en erken 15 yaşlarında olduğu saptandı. Kök gelişiminin tamamlanması kızlarda en erken 16, erkeklerde 17 yaşlarında olduğu bulundu.

\section{TEŞEKKür Ve ANmA}

Bu çalışma 8-13 Eylül 2014 tarihinde Hawai, Amerika Birleşik Devletleri'nde 96.'sı düzenlenen American Association of Oral and Maxillofacial Surgeons yıllık bilimsel toplantısında poster bildirisi şeklinde sunulmuş ve özeti yayımlanmıştır: Uzuner FD, Kaygisiz E, Yeniay A, Darendeliler N, Zor ZF. Radiographic evaluation of third molar development in relation to chronological age, gender and jaws. Journal of Oral and Maxillofacial Surgery, Volume 72, Issue 9, Supplement, September 2014, Pages e80-e81.

Çıkar çatışması: Yazarlar bu çalışmayla ilgili herhangi bir çıkar çatı̧̧malarının bulunmadığını bildirmişlerdir.

\section{KAYNAKLAR}

1. Lysell $L$, Rohlin M. A study of indications used for removal of the mandibular third molar. Int J Oral Maxillofac Surg 1988;17:161-4.

2. Richardson ME. The etiology and prediction of mandibular third molar impaction. Angle Orthod 1977;47:165-72.

3. Celikoglu M, Kamak H. Patterns of third-molar agenesis in an orthodontic patient population with different skeletal malocclusions. Angle Orthod 2012;82:165-9.

4. Arany S, lino M, Yoshioka N. Radiographic survey of third molar development in relation to chronological age among Japanese juveniles. J Forensic Sci 2004;49:534-8.

5. Bolaños MV, Moussa H, Manrique MC, Bolaños MJ. Radiographic evaluation of third molar development in Spanish children and young people. Forensic Sci Int 2003;133:212-9.

6. Kajii T, Imai T, Kajii S, lida J. Presence of third molar germs in orthodontic patients in Japan. Am J Orthod Dentofacial Orthop 2001;119:24550 .

7. Chaparro-Avendaño A, Pérez-García S, Valmaseda-Castellón E, Berini-Aytés L, Gay-Escoda C. Morbidity of third molar extraction in patients between 12 and 18 years of age. Med Oral Patol Oral Cir Bucal 2005;10:422-31.

8. Bruce RA, Frederickson GC, Small GS. Age of patients and morbidity associated with mandibular third molar surgery. J Am Dent Assoc 1980;101:240-5.

9. Chiles DG, Cosentino BJ. The third molar question: report of cases. J Am Dent Assoc 1987;115:575-6.

10. Zawawi $\mathrm{KH}$, Melis M. The role of mandibular third molars on lower anterior teeth crowding and relapse after orthodontic treatment: a systematic review. Scientific World Journal 2014;2014:615429.

11. Niedzielska I. Third molar influence on dental arch crowding. Eur J Orthod 2005;27:518-23.

12. Lindqvist $B$, Thilander $B$. Extraction of third molars in cases of anticipated crowding in the lower jaw. Am J Orthod 1982;81:130-9.

13. Sidlauskas A, Trakiniene G. Effect of the lower third molars on the lower dental arch crowding. Stomatologija 2006;8:80-4.

14. Buschang PH, Shulman JD. Incisor crowding in untreated persons 15-50 years of age: United States, 1988-1994. Angle Orthod 2003;73:502-8.
15. Chiapasco M, De Cicco L, Marrone G. Side effects and complications associated with third molar surgery. Oral Surg Oral Med Oral Pathol 1993;76:412-20.

16. Bishara SE. Third molars: A dilemma! Or is it? Am J Orthod Dentofacial Orthop 1999;115:628-33.

17. Gunst K, Mesotten K, Carbonez A, Willems G. Third molar development in relation to chronological age: a large sample sized retrospective study. Forensic Sci Int 2003;136:52-7.

18. Kullman $L$, Johanson $G$, Akesson $L$. Root development of the lower third molar and its relation to chronological age. Swed Dent J 1992;16:161-7.

19. Olze A, Taniguchi M, Schmeling A, Zhu BL, Yamada $Y$, Maeda $H$, et al. Studies on the chronology of third molar mineralization in a Japanese population. Leg Med (Tokyo) 2004;6:73-9.

20. Martin-de las Heras S, García-Fortea P, Ortega A, Zodocovich S, Valenzuela A. Third molar development according to chronological age in populations from Spanish and Magrebian origin. Forensic Sci Int 2008; $174: 47-53$.

21. Orhan K, Ozer L, Orhan AI, Dogan S, Paksoy CS. Radiographic evaluation of third-molar development in relation to chronological age among Turkish children and youth. Forensic Sci Int 2007;165:46-51.

22. Liversidge HM. Timing of human mandibular third molar formation. Ann Hum Biol 2008,35:294-321.

23. Olze A, Schmeling A, Taniguchi M, Maeda $H$, Van Niekerk $P$, Wernecke KD, et al. Forensic age estimation in living subjects: the ethnic factor in wisdom teeth mineralization. Int J Leg Med 2004;118:170-3.

24. Jafari A, Mohebbi S, Khami M, Shahabi MS, Naseh M, Elhami F, et al. Radiographic evaluation of third molar development in 5-25 years old in Tehran, Iran. J Dent (Tehran) 2012;9:107-15.

25. Uzamış M, Kansu Ö, Taner TU, Alpar R. Radiographic evaluation of third-molar development in a group of Turkish children. ASDC J Dent Child 2000;67:136-41.

26. Olze A, Taniguchi M, Schmeling A, Zhu BL, Yamada Y, Maeda H, et al. Comparative study on the chronology of third-molar mineralization in a Japanese and a German population. Leg Med 2003;5:256-60.

27. Şişman Y, Uysal T, Yağmur F, Ramoglu SI. Third-molar development in relation to chronologic age in Turkish children and young adults. Angle Orthod 2007;77:1040-5.

28. Karatas OH, Öztürk F, Dedeoğlu N, Çolak C, Altun O. Radiographic evaluation of third-molar development in relation to the chronological age of Turkish children in the southwest eastern Anatolia region. Forensic Sci Int 2013;:238:e1-5.

29. Tunc ES, Koyuturk AE. Dental age assessment using Demirjian's method on northern Turkish children. Forensic Sci Int 2008;175:23-6.

30. Demirjian A, Goldstein H, Tanner JM. A new system of dental age assessment. Hum Biol 1973;45:211-27.

31. Krailassiri S, Anuwongnukroh N, Dechkunakorn S. Relationship between dental calcification stages and skeletal maturity indicators in Thai individuals. Angle Orthod 2002;72:155-66.

32. Jung $\mathrm{YH}$, Cho BH. Radiographic evaluation of third molar development in 6 to 24 year olds. Imaging Sci Dent 2014;44:185-91.

33. Preshaw PM, Fisher SE. Routine review of patients after extraction of third molars: is it justified. Br J Oral Maxillofac Surg 1997;35:393-5.

34. Cantekin K, Sekerci AE, Buyuk SK. Dental computed tomographic imaging as age estimation: morphological analysis of the third molar of a group of Turkish population. Am J Forensic Med Pathol 2013;34:357-62. 35. Haavikko $\mathrm{K}$. The formation and the alveolar and clinical eruption of the permanent teeth: an orthopantomographic study. Proc Finn Dent Soc 1970;66:103-70.

36. Harris EF. Mineralization of the mandibular third molar: a study of American blacks and whites. Am J Phys Anthropol 2007;132:98-109.

37. Karadayi B, Kaya A, Kolusayın MO, Karadayi S, Afsin H, Ozaslan A. Radiological age estimation: based on third molar mineralization and eruption in Turkish children and young adults. Int $\mathrm{J}$ Legal Med 2012;126:933-42.

38. Solari AC, Abramovitch K. The accuracy and precision of third molar development as an indicator of chronological age in Hispanics. $J$ Forensic Sci 2002;47:531-5. 


\section{Radiographic evaluation of the third molar development in a Turkish population: age, sex and jaw comparison}

\begin{abstract}
OBJECTIVE: The aim of the study was to determine and compare the developmental stages of the third molars in a sample of Turkish population aged between 12-17 years, according to age, sex and jaws.

MATERIALS AND MEtHOD: Orthopantomograms of 322 (162 female, 159 male) Turkish patients, aged between 12-17 years were examined. Patients that had maxillary and mandibular third molars on the left side were included to this study. Numbers of the teeth were similar in each age group and gender. All evaluations were done in a dark room by an experienced orthodontist blinded to the age and sex of the patients. Maxillary and mandibular thirdmolar developmental stages were evaluated according to
\end{abstract}

the Demirjian method (stages A-H). Each stage was assigned a numeric value from 1 to 8 . Mann-Whitney $U$ test was performed to determine the differences between age, sex and jaw. A p value less than 0.05 was considered as statistically significant.

RESULTS: The intraobserver reliability was $\mathbf{0 . 8 5}$. In all age categories, there was no statistically significant difference between the third molar development in different sexes or jaws. Third molar crown formation was observed to be completed at around the age of 14 in both sexes and jaws. One-half to two-thirds of the roots formed in both sexes and jaws earliest at about 15 years of age. Moreover, complete root development was as early as at $\mathbf{1 6}$ years for females and at 17 years for males.

Conclusion: At each age, no significant difference was found in the third molar development between males and females, and between maxilla and mandible.

KEYWORDS: Molar, third; tooth eruption; tooth calcification 